\title{
Nomogram for predicting overall survival in colorectal cancer with distant metastasis
}

\author{
Zheng Liu' ${ }^{1,2,9}$, Yao Xu ${ }^{1,9}$, Guijun Xu13,3,9, Vladimir P. Baklaushev ${ }^{4,9}$, Vladimir P. Chekhonin ${ }^{5,9}$, Karl Peltzer ${ }^{6}$, \\ Wenjuan Ma ${ }^{7,9}$, Xin Wang ${ }^{8,9}$, Guowen Wang ${ }^{1,9^{*}}$ and Chao Zhang ${ }^{1,9^{*}}$
}

\begin{abstract}
Background: Colorectal cancer (CRC) is a major cancer burden, and prognosis is determined by many demographic and clinicopathologic factors. The present study aimed to construct a prognostic nomogram for colorectal cancer patients with distant metastasis.

Methods: Colorectal cancer patients with distant metastasis diagnosed between 2010 and 2016 were selected from the Surveillance, Epidemiology, and End Results database. Cox proportional hazards regression was used to identify independent prognostic factors. A nomogram was constructed to predict survival, and validation was performed.

Results: A total of 7099 stage IV colorectal cancer patients were enrolled in the construction cohort. The median overall survival was 20.0 (95\% Cl 19.3-20.7) months. Age at diagnosis, marital status, race, primary tumour site, tumour grade, CEA level, T stage, N stage, presence of bone, brain, liver and lung metastasis, surgery for primary site and performance of chemotherapy were independent prognostic factors. The nomogram was constructed and the calibration curve showed satisfactory agreement. The C-index was $0.742(95 \% \mathrm{Cl} 0.726-0.758)$. In the validation cohort (7098 patients), the nomogram showed satisfactory discrimination and calibration with a C-index of $0.746(95 \% \mathrm{Cl}$ 0.730-0.762).

Conclusion: A series of factors associated with the survival of CRC patients with distant metastasis were found. Based on the identified factors, a nomogram was generated to predict the survival of stage IV colorectal cancer patients. The predictive model showed satisfactory discrimination and calibration, which can provide a reference for survival estimation and individualized treatment decisions.
\end{abstract}

Keywords: Colorectal neoplasms, Stage IV, Overall survival, Nomograms, SEER program

\section{Background}

Colorectal cancer $(\mathrm{CRC})$ is the third most frequent cancer and one of the main causes of cancer-related death [1]. In 2016, there were 1,700,000 new CRC cases and 830,000 deaths attributed to CRC worldwide [2]. Although treatment strategies, such as immunotherapy, chemotherapy

\footnotetext{
*Correspondence: wangguowen@tmu.edu.cn; drzhangchao@tmu.edu.cn ${ }^{1}$ Department of Bone and Soft Tissue Tumors, Tianjin Medical University Cancer Institute and Hospital, National Clinical Research Center for Cancer, Key Laboratory of Cancer Prevention and Therapy, Tianjin's Clinical Research Center for Cancer, Tianjin 300060, China

Full list of author information is available at the end of the article
}

and targeted agents, have been developing rapidly in recent decades, the prognosis of CRC is still unsatisfactory [3-5]. It was reported that the 5-year overall mortality rate was $65.0-70.0 \%$ for stage III CRC patients [6, 7]. Compared to patients without metastasis, the survival outcome of metastatic CRC patients was worse, with a 5-year survival rate of only $14.0 \%$ [8]. A previous study analysed 374 stage IV CRC patients and suggested that synchronous metastatic CRC patients had worse 3-year survival (33.0\%) than metachronous CRC patients (54.0\%, $P=0.0038$ ) [9]. The incidence of synchronous distant metastasis was reported to be increasing in the latest study, with rates of $15 \%-20 \%$ in CRC patients $[10,11]$.

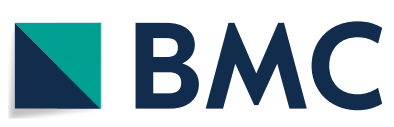

(c) The Author(s) 2021. Open Access This article is licensed under a Creative Commons Attribution 4.0 International License, which permits use, sharing, adaptation, distribution and reproduction in any medium or format, as long as you give appropriate credit to the original author(s) and the source, provide a link to the Creative Commons licence, and indicate if changes were made. The images or other third party material in this article are included in the article's Creative Commons licence, unless indicated otherwise in a credit line to the material. If material is not included in the article's Creative Commons licence and your intended use is not permitted by statutory regulation or exceeds the permitted use, you will need to obtain permission directly from the copyright holder. To view a copy of this licence, visit http://creativecommons.org/licenses/by/4.0/. The Creative Commons Public Domain Dedication waiver (http://creativeco $\mathrm{mmons}$.org/publicdomain/zero/1.0/) applies to the data made available in this article, unless otherwise stated in a credit line to the data. 
Survival of patients with distant metastasis significantly affects the organization of individualized treatment. Thus, studies focusing on survival estimation of initial stage IV CRC are urgently needed.

Various prognostic factors for stage IV CRC patients have been investigated in previous studies. Several demographic and clinicopathologic variables were proven to be independent prognostic factors: age at diagnosis [11], tumour size [12], lymph metastasis [12], resectability [12], and chemotherapy treatment [10]. Carcinoembryonic antigen (CEA) levels and primary tumour sites were reported to be associated with the survival of CRC [9, 13]. In a multicentre register study comprising 9624 stage IV CRC patients, a prognostic scoring system was established based on eight independent prognostic factors. The total score was ranged from 0 to 9 , and higher scores indicated poorer survival $[9,13]$.

Nomograms are widely used as graphical prediction models, by which survival predictive points can be calculated based on the predictors [15]. Several prognostic nomograms for stage IV CRC have been constructed in recent years [16-18]. Based on 1133 stage IV CRC patients who received curative resection, nomograms to predict disease-free survival (DFS) and overall survival (OS) were constructed [16]. However, only four predictors ( $\mathrm{T}$ stage, $\mathrm{N}$ stage, postoperative CEA and metastatic organs) were included in the models, which led to potential inaccuracy. In 2019, Hua Ge et al. reported a nomogram to predict OS in CRC patients at M1 stage [17]. Several social characteristics and tumour-related variables were included in the nomogram. Nevertheless, neither serum CEA level nor the performance of adjuvant treatment (radiation and chemotherapy) were included as predictors, which are widely considered independent prognostic factors for CRC patients [13]. Another SEER-based study enrolled 2996 CRC patients with stage IV disease, and a predictive nomogram was constructed [18]. External validation was performed based on a Chinese cohort with high discrimination (C-index of OS: $0.657 ; 95 \%$ CI $0.544-0.770$ ), which indicated good transportability of the nomogram [18]. However, the nomogram was used to predict the survival of patients who underwent both primary and metastatic resection. A nomogram including as many necessary predictors as possible is urgently needed to accurately estimate the current survival of stage IV CRC.

Extracting data from the Surveillance Epidemiology and End Results (SEER) database, the present study aimed to identify prognostic factors for CRC patients with distant metastasis. The factors were then used to construct a prognostic prediction nomogram. The predictive model can help oncologists accurately estimate prognosis and guide the individualized treatment.

\section{Methods}

Data source and cohort selection

Data were extracted from the Surveillance Epidemiology and End Results (SEER) database of the National Cancer Institute (https://seer.cancer.gov/), which covers approximately $30 \%$ of the US population. The SEER program provides information on cancer statistics to reduce cancer burden and all authors are permitted to access the original data without informed consent. The present study complied with the 1964 Declaration of Helsinki and its later amendments or comparable ethical standards.

The database, which was Incidence-SEER 18 Regs Custom Data (with additional treatment fields), Nov 2018 Sub (1975-2016 varying), was released in April 2019 and was selected as the data source for the present study. Patients with malignant colorectal cancer were extracted from the database according to the Site recode ICD-O-3/WHO 2008 of 'Colon and Rectum' and the Behavior recode for analysis of 'Malignant'. The year of diagnosis was restricted between 2010 and 2016 since data involving metastatic sites were not available until 2010. The exclusion criteria were as follows: (1) colorectal cancer cases from stage I-III; (2) two or more primary tumours; (3) diagnosed at autopsy or via death certificate; and (4) cases with unknown information about demographic and clinicopathologic variables. A detailed flow-chart for patient selection is shown in Fig. 1.

\section{Demographic and clinicopathologic variables}

The following demographic and clinicopathologic variables were included in the present study: age at diagnosis ( $<65$ and $\geq 65$ years), gender (male and female), marital status (married and unmarried), race (white, black and others), insurance status (insured and uninsured), primary site (left colon, right colon and other sites), tumour grade (I to IV: well, moderately, poorly and undifferentiated, respectively), carcinoembryonic antigen (CEA) level (normal and elevated), T stage (T1, T2, T3 and T4), N stage (N0, N1 and N2), the presence of bone, brain, liver, lung metastasis (no, yes), surgery for primary site (no, yes), radiation treatment (no/unknown, yes) and the performance of chemotherapy (no/unknown, yes). According to the Primary Site - labeled, the primary site was divided into 'Left colon' (C18.5-Splenic flexure of colon, C18.6-Descending colon, C18.7-Sigmoid colon, C19.9Rectosigmoid junction and C20.9-Rectum, NOS), 'Right colon' (C18.0-Cecum, C18.1-Appendix, C18.2-Ascending colon, C18.3-Hepatic flexure of colon and C18.4-Transverse colon) and 'Other sites' (C18.8-Overlapping lesion of colon and C18.9-Colon, NOS) categories. 


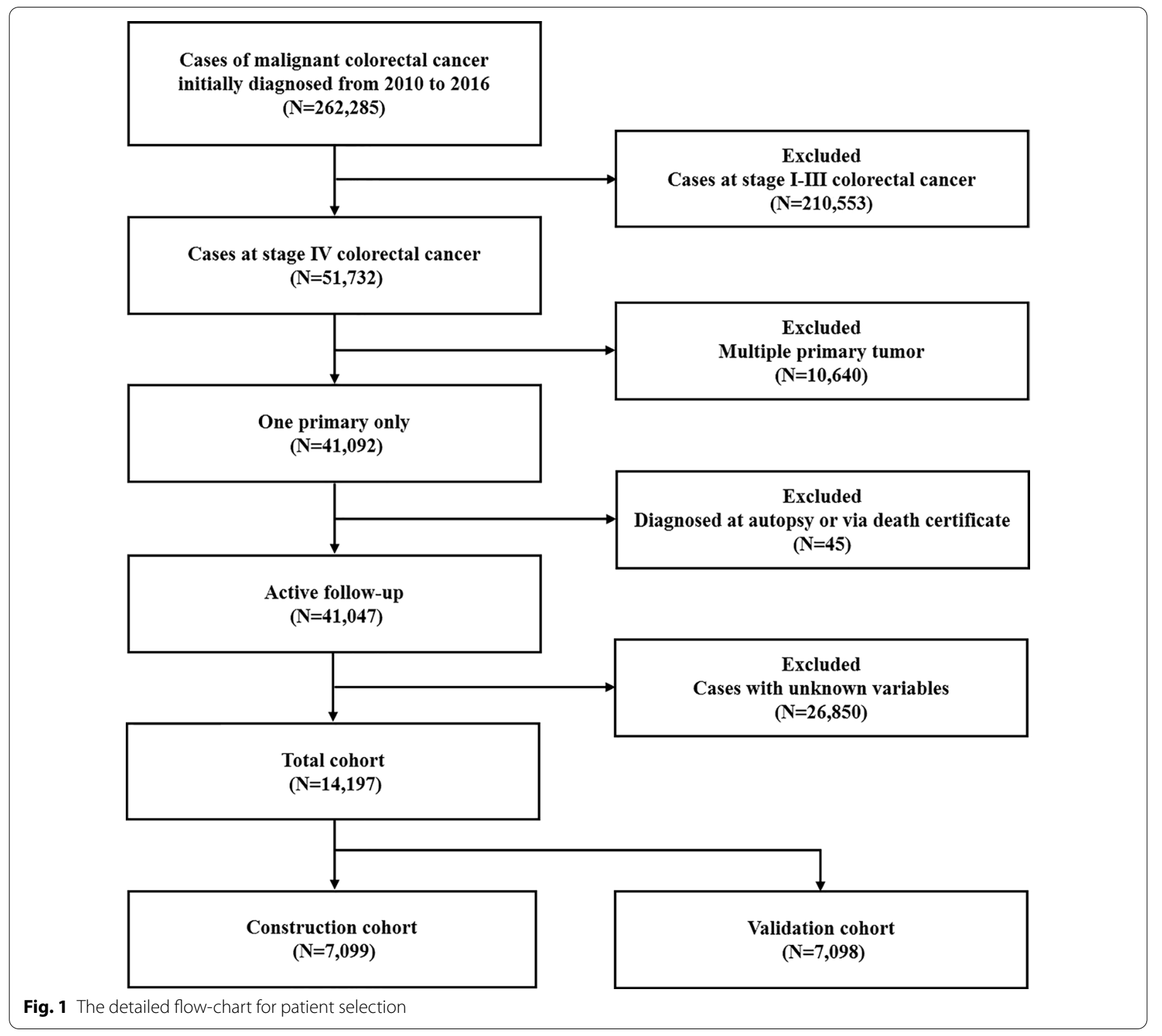

\section{Statistical analysis}

In the present study, the total cohort was randomly subdivided into construction and validation cohorts (ratio 1:1). A construction cohort was used to identify prognostic factors for stage IV colorectal cancer patients, and a nomogram was constructed, while the validation cohort was used to validate the performance of the model. Quantitative data are described as the mean \pm standard deviation (SD), while categorical variables are presented as numbers and percentages $(\mathrm{N}, \%)$. The primary outcome was overall survival (OS), which was defined as the time from diagnosis of colorectal cancer to all causes of death. Cox proportional hazards regression was performed to identify prognostic factors. Variables with significant differences in the univariate analysis were further analysed with a multivariate analysis to determine the independent prognostic factors. Based on the prognostic factors, the nomogram was formulated using the survival package in $R$. Each predictor included in the nomogram was represented on one row, and a corresponding number of points was assigned to different magnitudes of the predictor. The cumulative point axis was represented at the end of the nomogram, and higher total points indicated a worse survival outcome. The discriminative ability of the model was evaluated with Harrell's concordance index (C-index) and receiver operating characteristic (ROC) curve analysis. A larger C-index value and a greater area under the curve (AUC) in the 
ROC curve indicated better discrimination ability. Calibration curves (1000 bootstrap resamples) were generated to evaluate the calibration ability of the nomogram.

The case listing session of the SEER"Stat 8.3.6 program was used to generate data and IBM SPSS Statistics (version 26.0, Armonk, NY, USA) was used for statistical analyses. The construction of the prognostic nomogram and subsequent validation were performed with $R$ version 4.0.0 ( $\mathrm{R}$ Foundation for Statistical Computing, Vienna, Austria; www.r-project.org). All statistical tests were two-sided, and $P<0.05$ was considered significant.

\section{Results}

\section{Demographic and clinicopathologic characteristics}

According to the inclusion and exclusion criteria, a total of 7099 patients with stage IV colorectal cancer were included in the construction cohort. The mean age was $61.5 \pm 13.7$ years, with a slight predominance for male $(\mathrm{N}=3782,53.3 \%)$ and married $(\mathrm{N}=3880,54.7 \%)$ patients. The majority of the construction population was white $(\mathrm{N}=5358,75.8 \%)$ and insured $(\mathrm{N}=6755$, 95.2\%). Tumour grade I, grade II, grade III and grade IV accounted for $5.4 \%, 64.5 \%, 25.1 \%$ and $5.0 \%$, respectively. More than half of tumours $(\mathrm{N}=3948,55.6 \%)$ occurred in the left colon, while $42.3 \%$ were located in the right colon. The number of cases with elevated CEA was 5604, accounting for $78.9 \%$ in the construction cohort. T3 stage $(\mathrm{N}=3362,47.4 \%)$ was the most common tumour stage, followed by $\mathrm{T} 4$ stage $(\mathrm{N}=2885,40.6 \%)$, T1 stage $(\mathrm{N}=653,9.2 \%)$ and $\mathrm{T} 2$ stage $(\mathrm{N}=199,2.8 \%)$. The percentage of patients with lymph node metastasis was $74.2 \%$. There were $284,78,5000$ and 1458 patients diagnosed with bone, brain, liver and lung metastasis, respectively. Regarding the treatment strategy, nearly $80 \%$ of patients underwent surgery for colorectal tumour sites. Radiation and chemotherapy were administered to 939 and 5299 patients, respectively. Detailed information about the demographic and clinicopathologic characteristics of the validation cohort is shown in Table 1.

\section{Survival and prognostic factors of stage IV colorectal cancer}

A total of 4616 patients decreased in the construction cohort and the median overall survival (OS) was 20.0 (95\% CI 19.3-20.7) months. The 1-, 3- and 5-year OS rates were $64.8 \%, 28.7 \%$ and $15.4 \%$, respectively. In the univariate Cox regression analysis, the following variables were associated with survival: age at diagnosis, marital status, race, insurance status, primary site, tumour grade, CEA level, $\mathrm{T}$ stage, $\mathrm{N}$ stage, the presence of bone, brain, liver, lung metastasis, surgery for primary site, radiation treatment and chemotherapy treatment. The multivariate analysis identified that age older than 65 years, unmarried status, black race, primary site on the right colon or other sites, higher tumour grade, elevated CEA level, lower $\mathrm{T}$ stage, higher $\mathrm{N}$ stage, the presence of bone, brain, liver and lung metastasis, no surgery for the primary site and no/unknown performance of chemotherapy were independent prognostic factors for worse survival. More details about the Cox proportional hazard regression are listed in Table 2.

\section{Construction and validation of the nomogram}

As shown in Fig. 2, the nomogram for predicting 1-, 3 - and 5-year survival was constructed based on the abovementioned prognostic factors. The $\mathrm{C}$-index for the prediction of OS was 0.742 (95\% CI 0.726-0.758), and the AUCs of the nomogram for 1-year, 3-years and 5-years were $80.8 \%, 76.1 \%$ and $77.0 \%$, respectively (Fig. 3a-c). The calibration curve revealed good agreement between the predicted and observed probabilities. All calibration curves were close to the 45-degree line (Fig. 3d-f for 1-year, 3-years and 5-years, respectively).

In the validation cohort, the nomogram showed satisfactory discrimination strength. The C-index was 0.746 (95\% CI 0.730-0.762), and the AUCs for 1-year, 3 -year and 5-year survival were $79.9 \%, 77.1 \%$ and $77.0 \%$, respectively (Fig. $4 \mathrm{a}-\mathrm{c}$ ). Excellent calibration ability was achieved with all calibration curves close to the 45-degree line (Fig. 4d-f for 1-year, 3-years and 5-years, respectively).

\section{Discussion}

In the present study, the demographic and clinicopathologic characteristics of stage IV colorectal cancer were described and the survival outcome was estimated. Previous data from four national colorectal cancer registers showed that the 3-year net survival rates of stage IV CRC patients were $20.5 \%-33.0 \%$ and $26.7 \%-38.5 \%$ for colon and rectal cancer, respectively[19]. Another single institution study reported that the 5-year OS was $19.1 \%$ for stage IV CRC [12]. Our study observed similar survival rates with the previous studies.

According to the Japanese Society for Cancer of the Colon and Rectum guidelines, resectability should be first considered when making clinical decisions [20]. Systematic chemotherapy and radiotherapy are recommended in unresectable CRC cases, while palliative care is encouraged for patients with end-stage disease [20]. Despite different treatments for patients at different stages, the guidelines do not clearly state the survival estimation for each patient. Undoubtedly, accurate survival estimation 
Table 1 Baseline demographic and clinicopathologic characteristics in the construction and validation cohort

\begin{tabular}{|c|c|c|c|c|}
\hline \multirow[t]{2}{*}{ Subject characteristics } & \multicolumn{2}{|c|}{ Construction cohort $(\mathrm{N}=7099)$} & \multicolumn{2}{|c|}{ Validation cohort $(\mathrm{N}=7098)$} \\
\hline & Alive $(\mathrm{N}, \%)$ & Dead (N, \%) & Alive $(\mathrm{N}, \%)$ & Dead (N, \%) \\
\hline \multicolumn{5}{|c|}{ Age $($ years, mean $=61.5 \pm 13.7 ;$ median $=61)$} \\
\hline$<65$ & $1679(67.6)$ & $2523(54.7)$ & $1765(68.2)$ & $2433(53.9)$ \\
\hline$\geq 65$ & $804(32.4)$ & $2093(45.3)$ & $823(31.8)$ & $2077(46.1)$ \\
\hline \multicolumn{5}{|l|}{ Gender } \\
\hline Male & $1295(52.2)$ & $2487(53.9)$ & $1329(51.4)$ & $2431(53.9)$ \\
\hline Female & $1188(47.8)$ & $2129(46.1)$ & 1259 (48.6) & $2079(46.1)$ \\
\hline \multicolumn{5}{|l|}{ Marital status } \\
\hline Married & $1494(60.2)$ & $2386(51.7)$ & $1568(60.6)$ & $2372(52.6)$ \\
\hline Unmarried & $989(39.8)$ & $2230(48.3)$ & $1020(39.4)$ & $2138(47.4)$ \\
\hline \multicolumn{5}{|l|}{ Race } \\
\hline White & $1885(75.9)$ & $3473(75.2)$ & $1983(76.6)$ & $3436(76.2)$ \\
\hline Black & $323(13.0)$ & $740(16.0)$ & $331(12.8)$ & $665(14.7)$ \\
\hline Others & $275(11.1)$ & $403(8.7)$ & $274(10.6)$ & $409(9.1)$ \\
\hline \multicolumn{5}{|l|}{ Insurance } \\
\hline Insured & 2398 (96.6) & 4357 (94.4) & 2457 (94.9) & 4253 (94.3) \\
\hline Uninsured & $85(3.4)$ & $259(5.6)$ & $131(5.1)$ & $257(5.7)$ \\
\hline \multicolumn{5}{|l|}{ Primary site } \\
\hline Left colon & 1525 (61.4) & $2423(52.5)$ & $1610(62.2)$ & 2335 (51.8) \\
\hline Right colon & 915 (36.9) & $2089(45.3)$ & $943(36.4)$ & $2056(45.6)$ \\
\hline Other sites & $43(1.7)$ & $104(2.3)$ & $35(1.4)$ & $119(2.6)$ \\
\hline \multicolumn{5}{|l|}{ Grade } \\
\hline Grade I & $160(6.4)$ & $222(4.8)$ & $181(7.0)$ & $198(4.4)$ \\
\hline Grade II & $1792(72.2)$ & $2790(60.4)$ & $1852(71.6)$ & $2787(61.8)$ \\
\hline Grade III & $445(17.9)$ & $1338(29.0)$ & $452(17.5)$ & $1248(27.7)$ \\
\hline Grade IV & $86(3.5)$ & $266(5.8)$ & $103(4.0)$ & $277(6.1)$ \\
\hline \multicolumn{5}{|l|}{ CEA } \\
\hline Normal & $661(26.6)$ & $834(18.1)$ & 748 (28.9) & $853(18.9)$ \\
\hline Elevated & $1822(73.4)$ & 3782 (81.9) & $1840(71.1)$ & 3657 (81.1) \\
\hline \multicolumn{5}{|l|}{ T stage } \\
\hline $\mathrm{T} 1$ & $140(5.6)$ & $513(11.1)$ & $154(6.0)$ & $493(10.9)$ \\
\hline $\mathrm{T} 2$ & $103(4.1)$ & $96(2.1)$ & $88(3.4)$ & $97(2.2)$ \\
\hline T3 & $1328(53.5)$ & $2034(44.1)$ & $1390(53.7)$ & $1992(44.2)$ \\
\hline $\mathrm{T} 4$ & $912(36.7)$ & $1973(42.7)$ & $956(36.9)$ & $1928(42.7)$ \\
\hline \multicolumn{5}{|l|}{ N stage } \\
\hline NO & $670(27)$ & $1159(25.1)$ & $703(27.2)$ & $1058(23.5)$ \\
\hline N1 & 1008 (40.6) & $1687(36.5)$ & $1066(41.2)$ & $1643(36.4)$ \\
\hline N2 & $805(32.4)$ & $1770(38.3)$ & $819(31.6)$ & $1809(40.1)$ \\
\hline \multicolumn{5}{|l|}{ Bone metastasis } \\
\hline No & $2434(98.0)$ & 4381 (94.9) & 2541 (98.2) & $4282(94.9)$ \\
\hline Yes & $49(2.0)$ & $235(5.1)$ & $47(1.8)$ & $228(5.1)$ \\
\hline \multicolumn{5}{|l|}{ Brain metastasis } \\
\hline No & 2468 (99.4) & 4553 (98.6) & 2574 (99.5) & 4457 (98.8) \\
\hline Yes & $15(0.6)$ & $63(1.4)$ & $14(0.5)$ & $53(1.2)$ \\
\hline \multicolumn{5}{|l|}{ Liver metastasis } \\
\hline No & 809 (32.6) & $1290(27.9)$ & $887(34.3)$ & $1188(26.3)$ \\
\hline Yes & 1674 (67.4) & $3326(72.1)$ & $1701(65.7)$ & $3322(73.7)$ \\
\hline \multicolumn{5}{|l|}{ Lung metastasis } \\
\hline No & 2061 (83.0) & $3580(77.6)$ & 2166 (83.7) & $3526(78.2)$ \\
\hline
\end{tabular}


Table 1 (continued)

\begin{tabular}{|c|c|c|c|c|}
\hline \multirow[t]{2}{*}{ Subject characteristics } & \multicolumn{2}{|c|}{ Construction cohort $(\mathrm{N}=7099)$} & \multicolumn{2}{|c|}{ Validation cohort $(\mathrm{N}=7098)$} \\
\hline & Alive (N, \%) & Dead (N, \%) & Alive (N, \%) & Dead (N, \%) \\
\hline Yes & $422(17.0)$ & $1036(22.4)$ & $422(16.3)$ & $984(21.8)$ \\
\hline \multicolumn{5}{|l|}{ Surgery for primary site } \\
\hline No & $379(15.3)$ & $1235(26.8)$ & $418(16.2)$ & $1152(25.5)$ \\
\hline Yes & $2104(84.7)$ & 3381 (73.2) & $2170(83.8)$ & $3358(74.5)$ \\
\hline \multicolumn{5}{|l|}{ Radiation } \\
\hline No/unknown & $2102(84.7)$ & $4058(87.9)$ & 2189 (84.6) & $3986(88.4)$ \\
\hline Yes & $381(15.3)$ & $558(12.1)$ & $399(15.4)$ & $524(11.6)$ \\
\hline \multicolumn{5}{|l|}{ Chemotherapy } \\
\hline No/unknown & $321(12.9)$ & $1479(32)$ & $305(11.8)$ & $1458(32.3)$ \\
\hline Yes & $2162(87.1)$ & $3137(68)$ & $2283(88.2)$ & $3052(67.7)$ \\
\hline
\end{tabular}

is a prerequisite for selecting the aforementioned clinical strategy. A total of fourteen independent prognostic factors were identified in the current study, and a predictive nomogram was constructed based on these predictors. The nomogram presented good discrimination and calibration in the validation cohort.

In the present study, chemotherapy was one of the predictors in the constructed nomogram, which was not previously included [16-18]. According to the Japanese Society for Cancer of the Colon and Rectum guidelines, postoperative adjuvant chemotherapy is recommended in patients with $\mathrm{R} 0$ resection [20]. In a retrospective study with 37.0 months of median follow-up, OS rates were $62.1 \%$ and $40.4 \%$ for CRC patients with and without adjuvant chemotherapy, respectively [13]. Another multi-institutional analysis reported that fewer recurrences were found in patients who received preoperative chemotherapy [10]. In addition, surgery for the primary site was another independent prognostic factor for stage IV CRC. Consistent with our study, no surgery was associated with a 2.807-fold increased risk of death in a previous study [17]. Compared to conventional open surgery, laparoscopic surgery showed advantages of reduced blood loss and shorter hospital stay [21]. No survival difference was found between the two surgical methods [22]. However, information on surgical methods and associated complications was not available in the SEER database.

Tumour grade was the most sensitive predictor in the current study, which was inconsistent with a previous SEER study [18]. This discrepancy may be attributed to the different study populations. In the previous study, only stage IV CRC patients who underwent primary and metastatic resection were included. However, all stage
IV CRC patients were selected for the present study. The latest study comprising $126 \mathrm{CRC}$ patients with distant metastasis concluded that grade classification was an independent prognostic factor [12]. Compared to patients with differentiated histology, the hazard ratio for patients with undifferentiated histology was 3.226 (95\% CI 1.558-6.711). The 5-year OS rates for patients with differentiated and undifferentiated histology were $21.1 \%$ and $11.1 \%$, respectively [12]. There is growing evidence that the primary tumour site is associated with survival of CRC patients. The outcome of patients with tumours in the left colon was better compared to patients with tumours in the right colon $[9,23]$. A retrospective SEER dataset reported that the right colon was more likely to present higher $\mathrm{T}$ stage and worse histology [23]. Another study concluded that there was increased expression of BRAF mutations in patients with right colon cancer, which was associated with worse survival [24]. The same trend was observed in the present study. The predictive model constructed by Hua Ge et al. indicated that survival of patients with tumour located in the rectum was better compared to patients with tumour located in other sites [17]. In the present study, the "Rectum" site was incorporated into "Left colon". We did not specifically analyse the survival outcome for patients with a tumour location in the rectum. Compared to the survival of patients with tumour located in different sites, our study suggested that patients with tumour located on overlapping lesions or with undetermined sites exhibited the worst survival.

In the present study, $\mathrm{T}$ stage, $\mathrm{N}$ stage and the presence of metastasis were proven to be prognostic factors. Thus, these factors were selected into the nomogram. As previously reported, these factors are widely accepted 
Table 2 Cox proportional hazard regression model for analyzing the prognostic factors for colorectal cancer patients at IV stage

\begin{tabular}{|c|c|c|c|c|}
\hline \multirow{2}{*}{$\begin{array}{l}\text { Subject } \\
\text { characteristics }\end{array}$} & \multicolumn{2}{|l|}{ Univariate } & \multicolumn{2}{|l|}{ Multivariate } \\
\hline & HR (95\% Cl) & $P$ value & HR (95\% Cl) & $P$ value \\
\hline \multicolumn{5}{|l|}{ Age } \\
\hline$<65$ & 1 (reference) & 1.00 & 1 (reference) & 1.00 \\
\hline$\geq 65$ & $1.60(1.51-1.70)$ & $<0.001$ & $1.37(1.29-1.46)$ & $<0.001$ \\
\hline \multicolumn{5}{|l|}{ Gender } \\
\hline Male & 1 (reference) & 1.00 & 1 (reference) & \\
\hline Female & $0.98(0.92-1.04)$ & 0.478 & - & - \\
\hline \multicolumn{5}{|l|}{ Marital status } \\
\hline Married & 1 (reference) & 1.00 & 1 (reference) & 1.00 \\
\hline Unmarried & $1.34(1.26-1.42)$ & $<0.001$ & $1.20(1.13-1.27)$ & $<0.001$ \\
\hline \multicolumn{5}{|l|}{ Race } \\
\hline White & 1 (reference) & 1.00 & 1 (reference) & 1.00 \\
\hline Black & $1.08(0.99-1.17)$ & 0.070 & $1.12(1.03-1.22)$ & 0.005 \\
\hline Others & $0.89(0.81-0.99)$ & 0.034 & $0.86(0.77-0.95)$ & 0.003 \\
\hline \multicolumn{5}{|l|}{ Insurance } \\
\hline Insured & 1 (reference) & 1.00 & 1 (reference) & 1.00 \\
\hline Uninsured & $1.25(1.10-1.42)$ & 0.001 & $1.13(0.99-1.29)$ & 0.066 \\
\hline \multicolumn{5}{|l|}{ Primary site } \\
\hline Left colon & 1 (reference) & 1.00 & 1 (reference) & 1.00 \\
\hline Right colon & $1.35(1.27-1.43)$ & $<0.001$ & $1.26(1.18-1.35)$ & $<0.001$ \\
\hline Other sites & $1.55(1.27-1.88)$ & $<0.001$ & $1.35(1.10-1.64)$ & 0.003 \\
\hline \multicolumn{5}{|l|}{ Grade } \\
\hline Grade I & 1 (reference) & 1.00 & 1 (reference) & 1.00 \\
\hline Grade II & $1.05(0.92-1.21)$ & 0.463 & $1.08(0.94-1.23)$ & 0.303 \\
\hline Grade III & $1.73(1.50-1.99)$ & $<0.001$ & $1.70(1.48-1.97)$ & $<0.001$ \\
\hline Grade IV & $1.80(1.50-2.15)$ & $<0.001$ & $1.93(1.61-2.32)$ & $<0.001$ \\
\hline \multicolumn{5}{|l|}{ CEA } \\
\hline Normal & 1 (reference) & 1.00 & 1 (reference) & 1.00 \\
\hline Elevated & $1.46(1.35-1.57)$ & $<0.001$ & $1.39(1.29-1.50)$ & $<0.001$ \\
\hline \multicolumn{5}{|l|}{ T stage } \\
\hline $\mathrm{T} 1$ & 1 (reference) & 1.00 & 1 (reference) & 1.00 \\
\hline $\mathrm{T} 2$ & $0.41(0.33-0.51)$ & $<0.001$ & $0.66(0.53-0.83)$ & $<0.001$ \\
\hline T3 & $0.54(0.49-0.60)$ & $<0.001$ & $0.84(0.75-0.95)$ & 0.004 \\
\hline T4 & $0.77(0.70-0.85)$ & $<0.001$ & $1.11(0.99-1.25)$ & 0.071 \\
\hline \multicolumn{5}{|l|}{ N stage } \\
\hline No & 1 (reference) & 1.00 & 1 (reference) & 1.00 \\
\hline N1 & $0.94(0.87-1.01)$ & 0.095 & $1.16(1.07-1.26)$ & $<0.001$ \\
\hline N2 & $1.15(1.07-1.24)$ & $<0.001$ & $1.55(1.43-1.69)$ & $<0.001$ \\
\hline \multicolumn{5}{|l|}{ Bone metastasis } \\
\hline No & 1 (reference) & 1.00 & 1 (reference) & 1.00 \\
\hline Yes & $2.02(1.77-2.30)$ & $<0.001$ & $1.57(1.37-1.80)$ & $<0.001$ \\
\hline \multicolumn{5}{|l|}{ Brain metastasis } \\
\hline No & 1 (reference) & 1.00 & 1 (reference) & 1.00 \\
\hline Yes & $1.98(1.54-2.54)$ & $<0.001$ & $1.44(1.11-1.86)$ & 0.005 \\
\hline \multicolumn{5}{|l|}{ Liver metastasis } \\
\hline No & 1 (reference) & 1.00 & 1 (reference) & 1.00 \\
\hline Yes & $1.12(1.05-1.19)$ & 0.001 & $1.34(1.25-1.43)$ & $<0.001$ \\
\hline
\end{tabular}

Table 2 (continued)

\begin{tabular}{|c|c|c|c|c|}
\hline \multirow{2}{*}{$\begin{array}{l}\text { Subject } \\
\text { characteristics }\end{array}$} & \multicolumn{2}{|l|}{ Univariate } & \multicolumn{2}{|l|}{ Multivariate } \\
\hline & $\mathrm{HR}(95 \% \mathrm{Cl})$ & $P$ value & HR $(95 \% \mathrm{Cl})$ & $P$ value \\
\hline \multicolumn{5}{|l|}{ Lung metastasis } \\
\hline No & 1 (reference) & 1.00 & 1 (reference) & 1.00 \\
\hline Yes & $1.37(1.28-1.47)$ & $<0.001$ & $1.30(1.21-1.4)$ & $<0.001$ \\
\hline \multicolumn{5}{|l|}{$\begin{array}{l}\text { Surgery for pri- } \\
\text { mary site }\end{array}$} \\
\hline No & 1 (reference) & 1.00 & 1 (reference) & 1.00 \\
\hline Yes & $0.53(0.49-0.56)$ & $<0.001$ & $0.43(0.39-0.47)$ & $<0.001$ \\
\hline \multicolumn{5}{|l|}{ Radiation } \\
\hline No/unknown & 1 (reference) & 1.00 & 1 (reference) & 1.00 \\
\hline Yes & $0.81(0.74-0.88)$ & $<0.001$ & $0.95(0.86-1.04)$ & 0.255 \\
\hline \multicolumn{5}{|l|}{ Chemotherapy } \\
\hline No/unknown & 1 (reference) & 1.00 & 1 (reference) & 1.00 \\
\hline Yes & $0.34(0.32-0.36)$ & $<0.001$ & $0.35(0.32-0.37)$ & $<0.001$ \\
\hline
\end{tabular}

$H R$ hazard ratio, $\mathrm{Cl}$ confidence interval

in various cancer prediction models [25, 26]. Consistent with other predictive models, higher $\mathrm{T}$ stage, higher $\mathrm{N}$ stage and increased sites of metastases indicated worse survival. Furthermore, several previous studies reported that elevated CEA levels indicated poor survival in CRC patients $[12,16]$. The aforementioned variables were incorporated into the predictive nomogram of CRC patients [14, 27].

There are some limitations in the current study. First, chemotherapy and radiation information in SEER is incomplete. Further study looking into chemotherapy and radiation on prognosis in stage IV colorectal cancer should be performed. Second, only internal validation was performed. The transportability of nomogram in additional patient populations should be validated in the future. Furthermore, detailed information about treatment, including surgical methods, chemotherapy regimens and targeted agents was not available in the current SEER database, and was reported to be associated with survival [22, 28]. Third, the present real-world study may overestimate the effect of the treatment (especially surgery) on the prognosis. To avoid the selection bias, a further randomized controlled trial on surgery should be performed to quantify such effect. Last but not least, cases with missing data were excluded. This may lead to the reduction of sample's representativeness. There could be substantial missing data bias due to the amount of missing data. The results might be different if there can be more complete data. Our study developed the auxiliary modelling for prognostic prediction in stage IV colorectal cancer. Such auxiliary tool should be carefully used based on the comprehensive situation of the patients. 


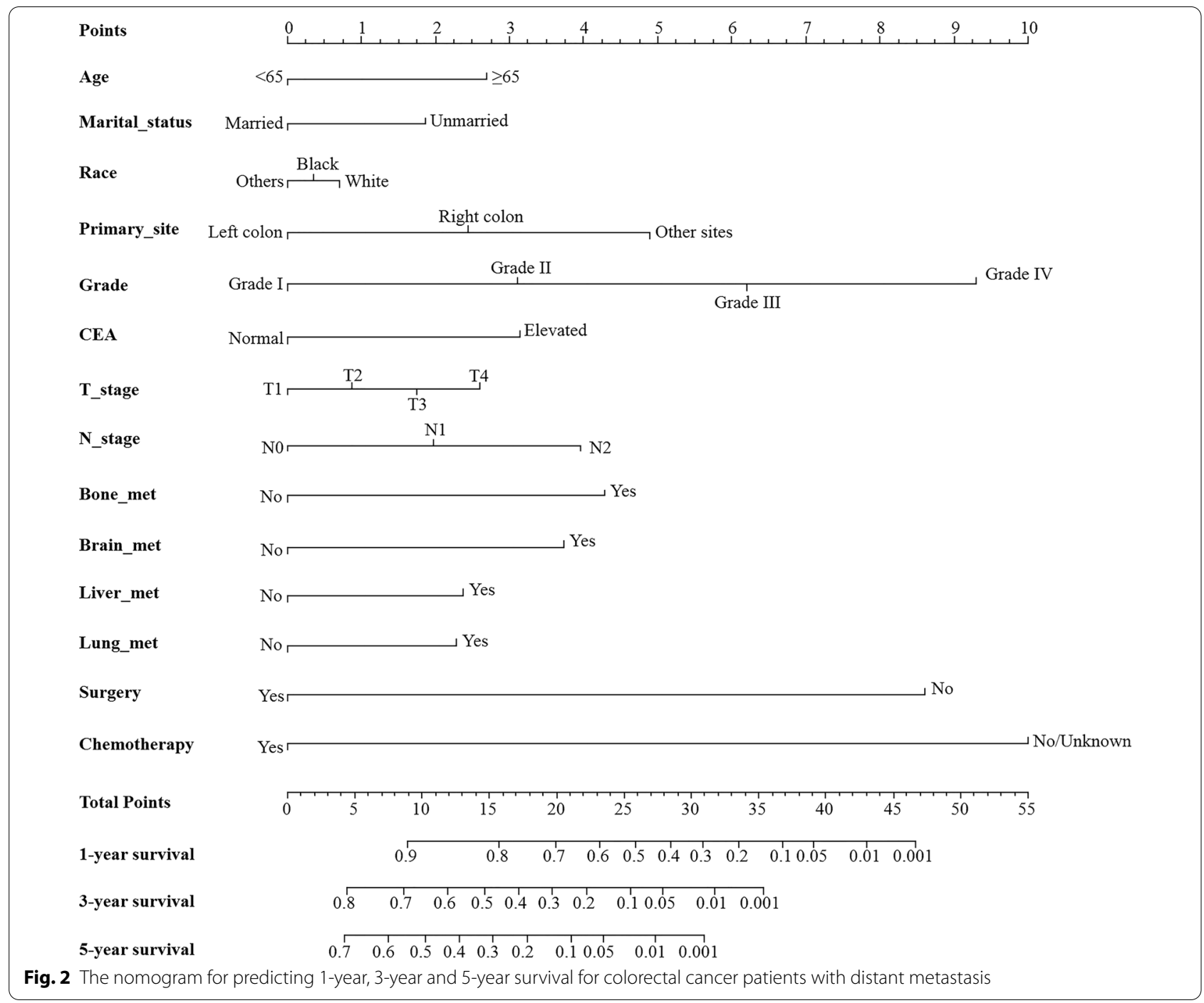



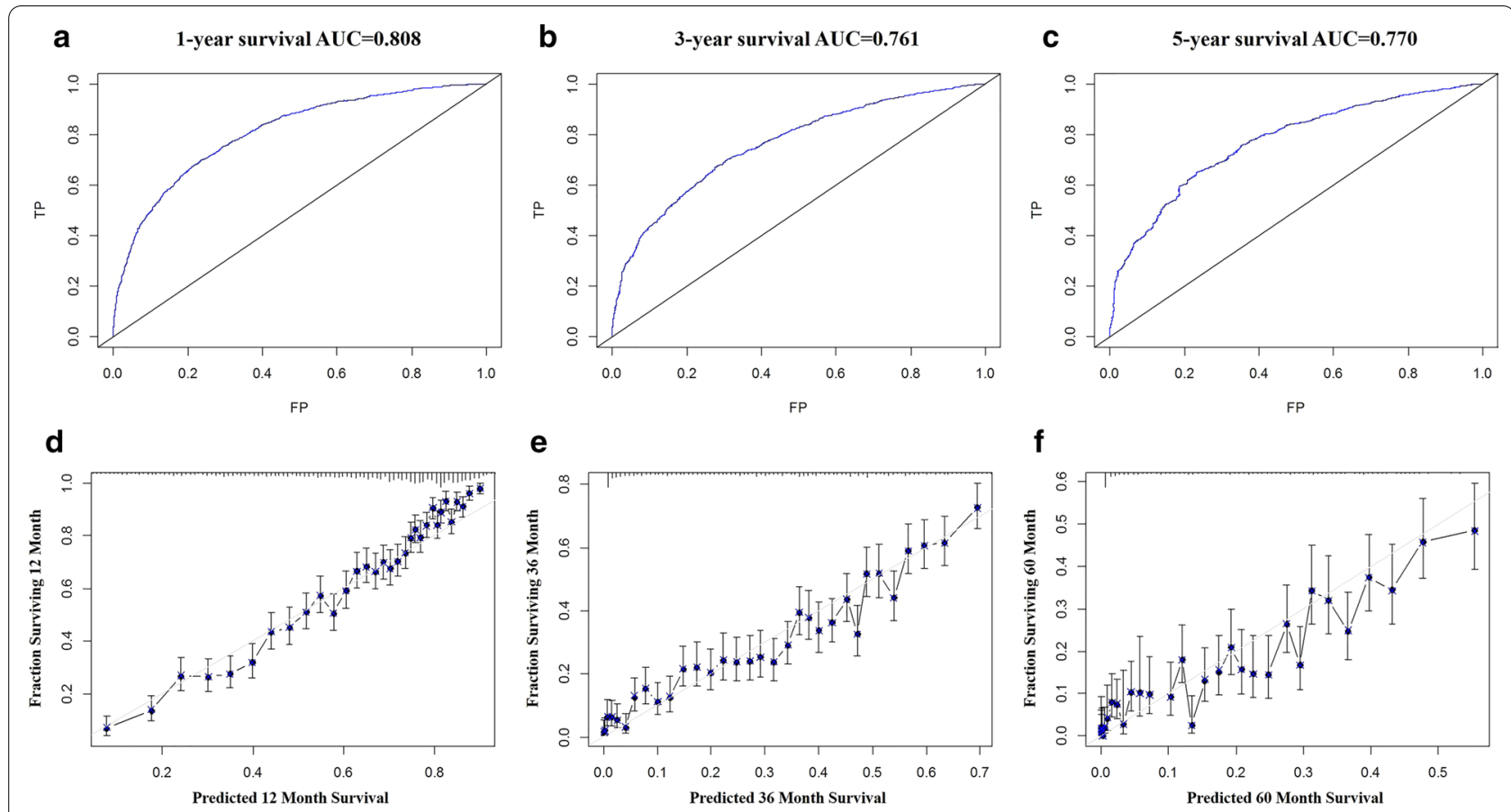

e

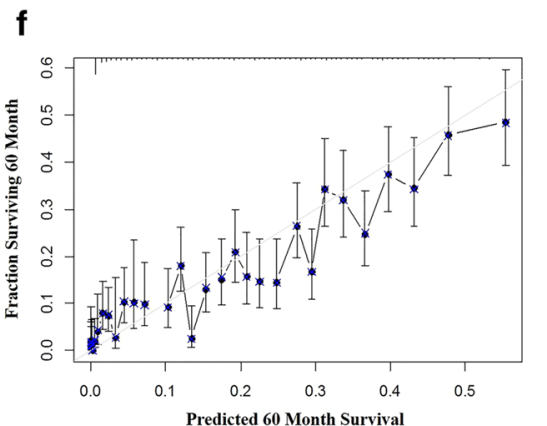

Fig. 3 The ROC curve (a-c) and calibration curve (d-f) for assessing the discrimination and calibration of the nomogram in construction cohort
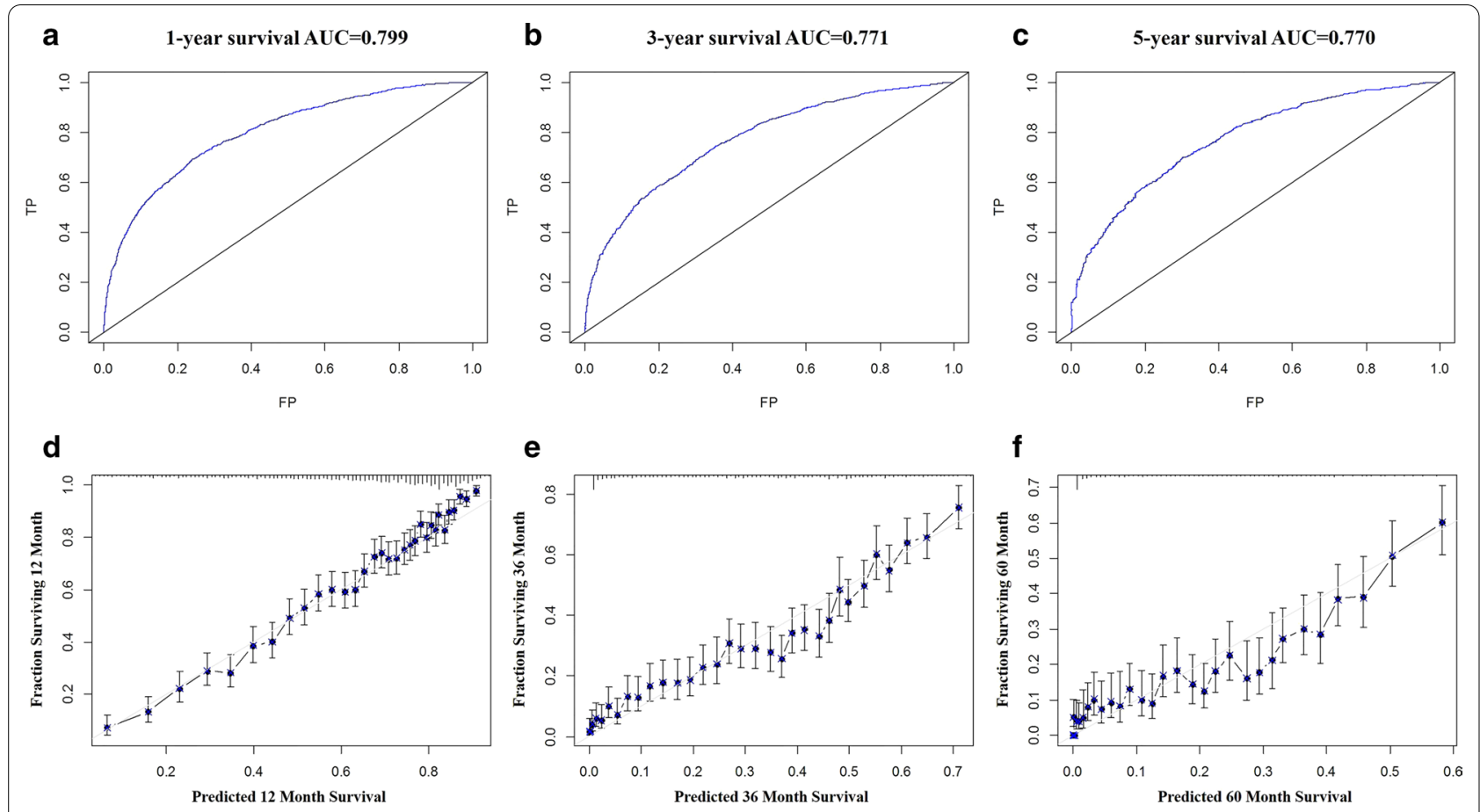

Fig. 4 The ROC curve $(\mathbf{a}-\mathbf{c})$ and calibration curve $(\mathbf{d}-\mathbf{f})$ for assessing the discrimination and calibration of the nomogram in validation cohort 


\section{Conclusions}

A prognostic nomogram for patients with stage IV colorectal cancer was constructed. The predictive model presented satisfactory discrimination and calibration, which can be used for survival estimation and individualized treatment decision-making in CRC patients with distant metastasis.

\section{Abbreviations}

CRC: Colorectal cancer; CEA: Carcinoembryonic antigen; DFS: Disease-free survival; OS: Overall survival; SEER: Surveillance Epidemiology and End Results; SD: Standard deviation; ROC: Receiver operating characteristic; AUC: Area under the curve; HR: Ratio; Cl: Confidence interval.

\section{Acknowledgments}

None.

\section{Authors' contributions}

Study conception and design: GW and CZ. Acquisition of data: YX and GX. Analysis and interpretation of data: WM and XW. Drafting of manuscript: ZL. Critical revision of manuscript: VPB, CPC and KP. All authors have read and approved the manuscript.

\section{Funding}

The present study was sponsored by the Natural Science Foundation of China (82011530050, 81903398).

\section{Availability of data and materials}

The datasets generated and analysed during the current study are available in the Surveillance, Epidemiology, and End Results database, [https://seer. cancer.gov/]. The database, which named as Incidence - SEER 18 Regs Custom Data (with additional treatment fields), Nov 2018 Sub (1975-2016 varying), was released in April 2019 and selected as the data source for the present study. The exclusion and inclusion criteria were stated in the section of Methods. The datasets are available from the corresponding author on reasonable request.

\section{Declarations}

Ethics approval and consent to participate

Not applicable.

\section{Consent for publication}

Not applicable.

\section{Competing interests}

The authors declare that they have no competing interests.

\footnotetext{
Author details

${ }^{1}$ Department of Bone and Soft Tissue Tumors, Tianjin Medical University Cancer Institute and Hospital, National Clinical Research Center for Cancer, Key Laboratory of Cancer Prevention and Therapy, Tianjin's Clinical Research Center for Cancer, Tianjin 300060, China. ${ }^{2}$ Department of Orthopedics, Heilongjiang Provincial Hospital, Harbin, Heilongjiang Province, China. ${ }^{3}$ Department of Orthopaedics, Tianjin Hospital, Tianjin, China. ${ }^{4}$ Federal Research and Clinical Center of Specialized Medical Care and Medical Technologies, Federal Biomedical Agency of the Russian Federation, Moscow, Russian Federation. ${ }^{5}$ Department of Basic and Applied Neurobiology, Federal Medical Research Center for Psychiatry and Narcology, Moscow, Russian Federation. ${ }^{6}$ Department of Research and Innovation, University of Limpopo, Turfloop, South Africa. ${ }^{7}$ Department of Breast Imaging, Tianjin Medical University Cancer Institute and Hospital, National Clinical Research Center for Cancer, Key Laboratory of Cancer Prevention and Therapy, Tianjin's Clinical Research Center for Cancer, Tianjin, China. ${ }^{8}$ Department of Epidemiology and Biostatistics, First Affiliated Hospital, Army Medical University, Chongqing, China. ${ }^{9}$ Sino-Russian Joint Research Center for Bone Metastasis in Malignant Tumor, Tianjin, China.
}

Received: 22 August 2020 Accepted: 24 February 2021

Published online: 04 March 2021

\section{References}

1. Siegel RL, Miller KD, Jemal A. Cancer statistics, 2019. CA Cancer J Clin. 2019;69:7-34.

2. Fitzmaurice C, Akinyemiju TF, Al LF, Alam T, Alizadeh-Navaei R, Allen C, et al. Global, regional, and national cancer incidence, mortality, years of life lost, years lived with disability, and Disability-Adjusted Life-Years for 29 cancer groups, 1990 to 2016: a systematic analysis for the global burden of disease study. JAMA Oncol. 2018;4:1553-68.

3. Riley JM, Cross AW, Paulos CM, Rubinstein MP, Wrangle J, Camp ER. The clinical implications of immunogenomics in colorectal cancer: a path for precision medicine. Cancer Am Cancer Soc. 2018;124:1650-9.

4. Woo IS, Jung YH. Metronomic chemotherapy in metastatic colorectal cancer. Cancer Lett. 2017:400:319-24.

5. Lee RM, Cardona K, Russell MC. Historical perspective: Two decades of progress in treating metastatic colorectal cancer. J Surg Oncol. 2019;119:549-63.

6. Zhou S, Wang X, Zhao C, Liu Q, Zhou H, Zheng Z, et al. Laparoscopic vs open colorectal cancer surgery in elderly patients: short- and long-term outcomes and predictors for overall and disease-free survival. BMC Surg. 2019;19:137.

7. Zhou Z, Mo S, Dai W, Xiang W, Han L, Li Q, et al. Prognostic nomograms for predicting cause-specific survival and overall survival of stage I-III colon cancer patients: a large population-based study. Cancer Cell Int. 2019;19:355.

8. Provenzale D, Gupta S, Ahnen DJ, Markowitz AJ, Chung DC, Mayer RJ, et al. NCCN guidelines insights: colorectal cancer screening, version 1.2018. J Natl Compr Canc Netw. 2018;16:939-49.

9. Suthananthan AE, Bhandari M, Platell C. Influence of primary site on metastatic distribution and survival in stage IV colorectal cancer. Anz J Surg. 2018;88:445-9.

10. Sato H, Maeda K, Morise Z, Takahashi H, Sugihara K. Clinical outcomes of stage IV colorectal cancer after R0 resection: a multi-institutional retrospective analysis. Int J Clin Oncol. 2017;22:297-306.

11. Yang L, Yang X, He W, Liu S, Jiang C, Xie K, et al. Comparisons of metastatic patterns of colorectal cancer among patients by age group: a population-based study. Aging. 2018;10:4107-19.

12. Sudo M, Furuya S, Shimizu H, Nakata Y, lino H, Shiraishi K, et al. Long-term outcomes after surgical resection in patients with stage IV colorectal cancer: A retrospective study of 129 patients at a single institution. World J Surg Oncol. 2019;17:56.

13. Huh JW, Lee WY, Park YA, Cho YB, Yun SH, Kim HC, et al. Prognostic factors associated with primary cancer in curatively resected stage IV colorectal cancer. J Cancer Res Clin. 2014;140:435-41.

14. Kobayashi $H$, Kotake K, Sugihara K. Prognostic scoring system for stage IV colorectal cancer: is the AJCC sub-classification of stage IV colorectal cancer appropriate? Int J Clin Oncol. 2013;18:696-703.

15. Bonnett $\sqcup$, Snell KIE, Collins GS, Riley RD. Guide to presenting clinical prediction models for use in clinical settings. BMJ. 2019;365:1737.

16. Kawai K, Ishihara S, Yamaguchi H, Sunami E, Kitayama J, Miyata H, et al. Nomograms for predicting the prognosis of stage IV colorectal cancer after curative resection: a multicenter retrospective study. Eur J Surg Oncol. 2015;41:457-65.

17. Ge H, Yan Y, Xie M, Guo L, Tang D. Construction of a nomogram to predict overall survival for patients with M1 stage of colorectal cancer: a retrospective cohort study. Int J Surg. 2019;72:96-101.

18. Zhang J, Gong Z, Gong Y, Guo W. Development and validation of nomograms for prediction of overall survival and cancer-specific survival of patients with Stage IV colorectal cancer. Jpn J Clin Oncol. 2019;49:438-46.

19. Benitez MS, Di Girolamo C, Rachet B, Maringe C, Guren MG, Glimelius B, et al. Surgical treatment and survival from colorectal cancer in Denmark, England, Norway, and Sweden: a population-based study. Lancet Oncol. 2019;20:74-87. 
20. Hashiguchi Y, Muro K, Saito Y, Ito Y, Ajioka Y, Hamaguchi T, et al. Japanese Society for Cancer of the Colon and Rectum (JSCCR) guidelines 2019 for the treatment of colorectal cancer. Int J Clin Oncol. 2020;25:1-42.

21. Nishikawa T, Ishihara S, Hata K, Murono K, Yasuda K, Otani K, et al. Shortterm outcomes of open versus laparoscopic surgery in elderly patients with colorectal cancer. Surg Endosc. 2016;30:5550-7.

22. Ishibe A, Ota M, Fujii S, Suwa Y, Suzuki S, Suwa H, et al. Midterm follow-up of a randomized trial of open surgery versus laparoscopic surgery in elderly patients with colorectal cancer. Surg Endosc. 2017;31:3890-7.

23. Zheng C, Jiang F, Lin H, Li S. Clinical characteristics and prognosis of different primary tumor location in colorectal cancer: a population-based cohort study. Clin Transl Oncol. 2019;21:1524-31.

24. Tapia Rico G, Price T, Tebbutt N, Hardingham J, Lee C, Buizen L, et al. Right or left primary site of colorectal cancer: outcomes from the molecular analysis of the AGITG MAX trial. Clin Colorectal Canc. 2019;18:141-8.

25. Zhang C, Mao M, Guo X, Cui P, Zhang L, Xu Y, et al. Nomogram based on homogeneous and heterogeneous associated factors for predicting bone metastases in patients with different histological types of lung cancer. BMC Cancer. 2019;19:238.
26. Wang X, Mao M, Xu G, Lin F, Sun P, Baklaushev VP, et al. The incidence, associated factors, and predictive nomogram for early death in stage IV colorectal cancer. Int J Colorectal Dis. 2019;34:1189-201.

27. Zhang Z, Luo Q, Yin X, Dai Z, Basnet S, Ge H. Nomograms to predict survival after colorectal cancer resection without preoperative therapy. BMC Cancer. 2016;16:658.

28. Price TJ, Tang M, Gibbs P, Haller DG, Peeters M, Arnold D, et al. Targeted therapy for metastatic colorectal cancer. Expert Rev Anticancer Ther. 2018;18:991-1006.

\section{Publisher's Note}

Springer Nature remains neutral with regard to jurisdictional claims in published maps and institutional affiliations.
Ready to submit your research? Choose BMC and benefit from:

- fast, convenient online submission

- thorough peer review by experienced researchers in your field

- rapid publication on acceptance

- support for research data, including large and complex data types

- gold Open Access which fosters wider collaboration and increased citations

- maximum visibility for your research: over $100 \mathrm{M}$ website views per year

At BMC, research is always in progress.

Learn more biomedcentral.com/submissions 